\title{
Research and Countermeasures on Information Demand and Information Behavior of Digital Youth Network in Colleges and Universities in Jilin Province
}

\author{
Limei Zhao ${ }^{1, a^{*}}$ and Enyang $\mathrm{Gao}^{2}$ \\ 1Jilin Engineering Normal University, Changchun,China,130052; \\ ${ }^{2}$ Shenyang Jianzhu University. Shenyang, China \\ a1060138576@qq.com, \\ ${ }^{*}$ corresponding author
}

\begin{abstract}
Keywords: College students information demand characteristic network environment multiculturalism
\end{abstract}

\begin{abstract}
Based on the college students as the research object, through to the recent research achievements of the characteristics of college students' information demand in China, the college students' information demand in recent years are summarized and summed up. In particular, the paper summarizes the research progress and shortcomings, and puts forward specific opinions and Suggestions on the change of the characteristics of the information demands of university students in the network environment and the multicultural culture.

With the rapid development of the times and the rapid development of modern science and technology, the characteristics of information demand of contemporary college students have changed a lot. The further development of information society has brought new challenges and new knowledge to college students, and the study of the characteristics of college students' information demand is conducive to find the obstacles and deficiencies of contemporary college students' finding information. To understand the characteristics of the information needs of contemporary college students, so as to improve the degree of information service work. In addition, according to the current research to further infer the future trend of college students' information demand, in order to promote the improvement of service facilities.
\end{abstract}

The information demand of college students refers to the reaction of college students' information consciousness to some information, which is affected by the information environment and other factors. The commonness of college students' information demand, that is, the diversity of information carrier and the response of the comprehensive information of information network Luo Du. It is influenced by information environment and personal knowledge structure, culture, information content novelty and information, personal ability, interest, intelligence. College students and information demand shows the characteristics of rapid growth and diversification, mainly is an important part of the knowledge audience, the study of college students' information demand is reflected in: the content of all; Diversity in the form; The multi-level university library has a comprehensive, systematic and in-depth understanding of the information needs of college students.

Principles of college students' information needs:

the demand for information value is extremely high.

the specialization of information is extremely high

accessibility requirements for information

timeliness of information

We believe that the university students in different periods of university information requirements are not the same. The early entry into the campus of the school information needs extremely high, we do not know what the university will bring us. After a year of experience, students are equipped with computers, the information of the network, our need for the network is constantly reflected. Coming out of campus, employment has become the biggest focus of our information needs. 
The information demand of the content, use form, carrier type and so on has certain universal young students' information demand is quite important, it has sex and the convergence. Among them, the demand and utilization of network information is more and more.

The characteristics of contemporary college students' demand for network information are characterized by stages, technicality and fashion. The information demand of young students is in the following form: the general rule of obtaining information demand and demand is not only academic, but also the demand for information exchange, information exchange and information consultation. University information needs, such as Chiung Yao fever, martial arts fever, biography hot, " Han Chao" and so on. The information demand of contemporary college students is more news, entertainment; The demand for academic or technical knowledge of the diversified characteristics of employment and school information and college students' information demand is relatively low. The demand for life, health and health reflects the diversity of the information needs of contemporary college students.

The content diversity of college students' information demand, the content of college students' information demand is rich and varied, there are hot information demand and specific content information demand.

Among them, the popular demand information mainly includes: using the basic knowledge of the library, specific content information needs, the researchers made more detailed, Liu Xue and in the college students' information demand survey found, Chinese and foreign graduation thesis materials, postgraduate entrance examination information, employment information, various types of examination information. Cutting the hot information needs of college students in normal colleges and universities focuses on how to use the library to complete their studies, to find papers writing materials, to help the graduate entrance examination information service and to obtain employment information in four aspects.

The characteristics of college students' information demand in multicultural culture

The pluralism of values, which leads to the pluralistic culture of college students' information demand, inevitably leads to the pluralistic values. Completely changed after the implementation of opening-up policy, our country closed semi-closed state in the internal and external environment, not only people's thought active unprecedentedly, and abroad of various thoughts, way of life also in, especially the western related to democracy and freedom, liberation of personality and cultural ideological trend influence. In order to meet the needs of society, to realize their own value, college students are no longer satisfied with read the professional literature information, but widely with the science of literature information, is keen on reading whatever is beneficial to the formation of world view, to broaden the knowledge, cultivating their scientific spirit, in order to improve the quality and the comprehensive level of the science book is popular among the students, their reading needs showed a certain universality.

The teaching arrangement and the focus on the hotspot issues show the concentration of college students' information needs. The unified arrangement of the school teaching plan, the syllabus and the teaching schedule will inevitably bring many college students in the same time to the relative concentration of the basic teaching reference materials. At the same time, the university student the thought is agile, particularly strong conformity, the campus culture and social trends and the influence of the major events that took place at home and abroad, also encourages college students more concentrated focus on popular books, for example, with the frequent exchanges with the rest of the world, the broad masses of students and unit of choose and employ persons the authority of the band four English certificate is considered an English show that this approach greatly stimulated the students' demands for English reading, English four, six levels of tests' book often in short supply. Also, the state senior economic management, law, accounting talents demand is still hot, making all kinds of economic theory, legal system construction of parties, such as books have flocked to the university library, and form a new reading tendency. In order to adapt to the need of information society, the university has opened a computer training accordingly and compulsory courses and elective courses, students readers to borrow a computer and books, the increasing demand of computer books. 
The information demand of college students is influenced by many factors, such as network technology, professional learning and research, self - development, conformity psychology, information environment and equipment.

The emergence and rapid development of the network has a profound impact on the information needs of college students, from content to form more rich and diverse, integrated efficient, and constantly to the direction of electronic, networking and socialization. The information demand appears socialization, individuation, integration, high efficiency, electronic, network and blindness, etc. The perfection of network facilities and the problem of network equipment usage fee are also the factors influencing the information demand of college students.

On the level of level, the information needs of college students and the level of educational background and the use of network information resources of university students are high, which is related to the traditional school level, and the trend of the printing information materials for doctoral students and undergraduates and junior college students; Comprehensive website and all kinds of entertainment have a clear distance.

In reality, the social environment has a lot of influence on it, and the life information has the greatest impact on it. To find and identify the information needs of the doctoral degree personnel has a certain similarity: other scientific methods and means: information demand is hierarchical, the existing relevant academic information demand, wide scope, timeliness, content - specific network information resources can not meet the in-depth development of college students' users in academic, especially foreign language data needs characteristics; The extent of the need for information needs.

Surveys show the highest use of the internet and campus networks, as well as the use of non normal channels such as the internet and peer exchanges, and even access to useful information in daily chat. Science and engineering school students pay more attention to the information of study abroad, professional students pay more attention to professional information, private college students pay more attention to job information, most of the school students prefer to obtain the information of the certificate.

The research methods of college students' information demand mainly include the following: first, use reading, consultation, computer and other records to make statistical analysis of the information demand type, quantity and subject content of different college students, so as to understand the college students' literature borrowing rate, borrowing cycle, information demand tendency, subject range, language structure, time span and other specific problems. Second, through talking, home message board, bulletin board, e - mail, etc., to understand the special needs of college students. Third, the use of census, sample surveys, typical surveys and other social survey methods to understand the characteristics of college students' information needs. The research methods of information users include questionnaire survey, statistical analysis, comparative analysis, correlation analysis, regression analysis, Delphi method, Markov analysis and so on. The study of college students' information needs should comprehensively and comprehensively use a variety of research methods, in order to understand and grasp the information needs of college students more accurately, and to provide them with related services.

The suggestions on the research of college students' information demand, to strengthen the prediction of college students' information demand, the information demand of college students is significantly characteristic compared with other types of personnel. Overall, the information needs of college students show the characteristics of stage and concentration, specifically, in the different stages of university study, the demand for the measurement is different. The junior college students mainly have more needs for the same or related reference books and literature materials as well as current affairs politics, news entertainment and so on. The senior students have a concentrated demand on the information materials related to the writing and employment and further study of the graduation thesis. Therefore, library and information workers should actively understand the characteristics of college students' information demand, grasp the key issues and hot issues, and strive to improve the self. 


\section{References}

[1] Fan xiaofeng. The characteristics of information demand of college students in multicultural environment [J]. Modern information, 2008 (1)

[2] Wang liangcheng. Research on information demand and use behavior of college students in network environment [J]. Intelligence science, 2002 (20)

[3] Huang yonghua. Analysis of the psychological characteristics of reading personality of college library college students [J]. Information management of scientific and technological documents, 2004, (2)

[4] Wu maorong, zhou. Information demand analysis of college students in higher education [J]. Scientific and technological intelligence development and economy, 2010 (20)

[5] Mo zhenxuan. Research on information demand of college students. Library study [J], 2006 (19).

[6] Sheng qiuyan. Liu xue and the information quality of college students in the Internet environment. Modern information [J], 2003 (12). 